REVISTA CHILENA DE LITERATURA

Diciembre 2016, Número 94, 79-100

\title{
SOCIABILIDAD Y NUEVAS TECNOLOGÍAS EN LAS PRÁCTICAS LECTORAS. UN ESTUDIO EN CIUDAD DE MÉXICO
}

\author{
Carla Pinochet Cobos \\ Universidad Alberto Hurtado \\ carlaasecas@gmail.com
}

\begin{abstract}
RESUMEN / ABSTRACT
Las nuevas tecnologías de la información han transformado de forma significativa las prácticas de lectura, promoviendo otras habilidades y competencias, y activando formas nuevas de vincularse con los dispositivos de lectura. En base a un estudio cualitativo realizado en la Ciudad de México, este artículo se propone indagar en los modos en que las innovaciones comunicacionales impactan en un tipo específico de lector, cuyo rasgo distintivo es tener una relación intensa y/o gozosa con la lectura: los creadores culturales. El análisis y reflexión en torno a estas prácticas permiten observar que, lejos de promover lectores aislados, las tecnologías emergentes desarrollan de otras maneras las potencialidades de sociabilidad de la lectura, estimulando la activación de redes de trabajo y proyectos colaborativos.

PALABRAS CLAVE: prácticas lectoras, creadores culturales, sociabilidad, nuevas tecnologías, redes sociales.

The new information technologies have transformed reading practices in meaningful ways, promoting other skills and competences, and activating new ways of interacting with reading devices. Based on a qualitative study conducted in Mexico City, this article aims to explore how communicational innovations have had an impact on a specific type of reader, whose distinctive feature is to have an intense and/or enjoyable relationship with the act of read: the cultural creators. The analysis of these practices and the reflection as a result of this, allows us to observe that, far from creating isolated readers, the emerging technologies contribute to develop, in other ways, the potential for the sociability of reading, thus stimulating work networks and collaborative projects.
\end{abstract}

KEYWORDS: Reading practices, cultural creators, sociability, new technologies, social networks. 
Este artículo busca entregar algunas claves, en el marco de las transformaciones contemporáneas activadas por las nuevas tecnologías, acerca de un particular perfil de lector. Frente al gran desafío que la inequidad social supone para los programas de fomento de la lectura, ocuparse de las prácticas de los creadores culturales parece un esfuerzo superfluo: si las encuestas nos han dibujado un dramático diagnóstico acerca de los índices de lectura en la población general, ¿para qué preocuparse de los que ya son lectores? Sin embargo, si modificamos la pregunta acerca de cuánto se lee para interrogarnos acerca de cómo se hace -en qué contextos, con qué fines, a partir de qué recursos-, encontramos en este tipo específico de lector un vasto horizonte de indagación. ¿Qué sabemos, hasta la fecha, de las prácticas de lectura de los creadores culturales? Las investigaciones que se han propuesto retratar a los sectores más aventajados pocas veces logran sustraerse de un espíritu desmitificador que casi siempre termina por explicar las prácticas de consumo cultural como mecanismos para reflejar estatus y distinción. Aunque no se puede desconocer el papel legitimador que puede tener el hecho de leer a los autores y títulos "indicados", lo cierto es que sus dinámicas concretas de lectura permanecieron invisibles, y las competencias lectoras de dichos sujetos se dieron por descontadas. Aunque los creadores culturales, por la frecuencia e intensidad de sus modos de lectura, constituyen un grupo de referencia para los programas de fomento lector, no sabemos prácticamente nada acerca de los modos específicos en los que ellos leen; qué competencias lectoras desarrollan; para qué utilizan la lectura; o qué papel tuvo ésta en la constitución de sus subjetividades individuales y colectivas. Cobra sentido, entonces, internarse en estos territorios, poniendo más atención al cómo que al cuánto.

A partir de una investigación etnográfica que tuvo lugar a lo largo de 2014 y 2015 en la Ciudad de México' ${ }^{1}$, damos cuenta aquí de un estudio que caracteriza las experiencias de lectura de un grupo amplio de artistas visuales y escritores, en tanto sujetos que han sido capaces de entablar un vínculo afectivo, productivo y complejo con los libros y los textos. Puesto

La investigación, realizada por Carla Pinochet Cobos y Verónica Gerber Bicecci, tuvo lugar en el marco del estudio "De la Galaxia Gutenberg a la Nube de Android. Cambios en los modos de leer" (2013-2015), coordinado por Néstor García Canclini desde el Departamento de Antropología de la Universidad Autónoma Metropolitana, Iztapalapa, México. Una versión más extensa de estos hallazgos fue publicada en "Hacia una antropología de los lectores" (2015), publicada por Editorial Ariel y Fundación Telefónica. 
que una investigación de este tipo corre el riesgo de retratar lo que Bourdieu llamó el "efecto de legitimidad"', y no interesa aquí reforzar la idea de que los creadores culturales son lectores asiduos sino describir sus prácticas lectoras efectivas, diseñamos una estrategia metodológica múltiple basada en entrevistas, autoobservación y grupos focales con el objeto de aprovechar e incorporar sus reflexiones y experiencias especializadas. Ésta consideró cuatro fases sucesivas: la realización de entrevistas en profundidad; la redacción por parte de los creadores culturales de biografias lectoras, en las que dieron cuenta del papel de la lectura en sus trayectorias; la elaboración de diarios de lectura, en los que artistas y escritores hicieron un seguimiento razonado de sus prácticas lectoras durante dos semanas corridas; y la ejecución de dos mesas de trabajo temáticas, en las que se presentaron y discutieron los hallazgos preliminares de la investigación. En total, participaron del estudio 52 creadores culturales de la Ciudad de México, que conformaron una muestra correspondientemente desagregada en términos de dos disciplinas (artistas visuales y escritores), de género y de rangos de edad (entre 20 y 35 años; entre 36 y 60 años).

El artículo que aquí presentamos pone especial atención a la dimensión de sociabilidad que atraviesa las prácticas lectoras de estos creadores culturales, en parte como consecuencia de un desarrollo tecnológico que dota de nuevos sentidos y formas de operación al acto de leer. Aunque no es posible en esta oportunidad ofrecer detalles extensos, este estudio incluyó, además, otros tres ejes temáticos que permitían dar cuenta en su conjunto del universo de prácticas y discursos que caracteriza las formas de leer de los artistas visuales y escritores de la ciudad de México.

En primer término, en la línea de las investigaciones que apuntan a que los modos de leer experimentan transformaciones a lo largo del tiempo (Chartier y Hébrard 89), registramos la configuración de las identidades lectoras de los sujetos a lo largo de sus biografías, poniendo de relieve los aspectos afectivos que se construyen con los libros y los textos.

En segundo lugar, nos propusimos caracterizar estas prácticas de lectoría sin el objeto de contruir perfiles excluyentes, pero dando cuenta de aquello que se repite y del repertorio de soluciones similares que ofrecen a problemas

2 Concepto que el autor describe de la siguiente manera: "cuando se le pregunta a alguien qué lee, entenderá: ¿qué es lo que leo que merezca ser mencionado? Es decir: ¿qué de lo que leo es, de hecho, literatura legítima?" (Bourdieu y Chartier 2010: 258). 
relativamente diversos. Concluimos, en este punto, que se trata de prácticas de lectura heterodoxas, que hacen uso simultáneo de recursos de lectura tradicionales y emergentes, y que comparten una forma de seleccionar, organizar y procesar los textos que llegan a sus manos: la lectura por proyectos (Gerber y Pinochet 200). Apuntamos también, en aquella oportunidad, los modos en que los creadores combinan recursos nuevos y formas tradicionales de lectura, proyectando la importancia de estas competencias híbridas a los contextos educacionales y las políticas culturales.

En tercer y último término, indagamos en las nuevas dimensiones materiales de la lectura: no solo han cambiado los objetos que hacen posible la lectura o los lugares físicos en los que los leemos; también se transforman las disposiciones corporales con las que nos enfrentamos a los textos y el contexto ambiental que envuelve estas prácticas. Observamos aquí cómo los soportes físicos se combinan de distintas maneras con los formatos digitales, promoviendo nuevas formas de interacción con la información. Este texto se detendrá en un cuarto eje de exploraciones, que plantea la necesidad de comprender la trama social que da forma a las prácticas de lectura, poniendo especial atención a las transformaciones que éstas experimentan con el advenimiento de las tecnologías y sus inéditas formas de comunicar espacios y tiempos distantes. Antes de proceder a estos hallazgos, nos interesa bosquejar algunas líneas de discusión que sirven de marco a las inquietudes de nuestro estudio.

\section{¿CÓMO OBSERVAR LA LECTURA?}

El extenso camino que han recorrido los estudios sociales en torno a las prácticas de lectura ha experimentado importantes transformaciones respecto de sus propósitos, sus marcos conceptuales de referencia y sus metodologías. Hacia fines de la década de 1970, las investigaciones sobre consumo cultural en Francia permiten distinguir dos líneas de trabajo que, en términos esquemáticos, representarán los dos polos conceptuales por los que oscilará el péndulo de los estudios de lectura. Por una parte, encabezadas por las reveladoras teorías de Pierre Bourdieu acerca de los correlatos socioeconómicos y simbólicos del consumo de bienes culturales, numerosas investigaciones asumieron el proyecto de describir las prácticas de lectura y su grado de legitimidad, preguntándose por cómo se construyen los sentidos sociales de los textos dentro de las relaciones de dominación. Por otro lado, más preocupadas por las formas de recepción de los bienes que por su valor simbólico estructural, 
planteamientos como los de Michel de Certeau o Paul Ricoeur se introducirán en el mundo de los lectores y su capacidad de agencia, explicitando la dimensión creativa y de reelaboración del sentido social que reside en todo acto de lectura. Así, si desde el primer enfoque resulta posible observar la existencia de lecturas diversas, con sus respectivas competencias y capacidades desiguales para apropiarse de los libros (Bourdieu y Chartier); la segunda de estas perspectivas permite distinguir los modos en que la experiencia de los lectores los lleva más allá del consumo pasivo, haciéndolos participantes de las disputas sobre lo que se produce y los modos de utilizarlo.

Aún en la complejidad del panorama actual de los estudios de lectura, estas dos grandes opciones teóricas siguen inspirando la mayor parte de las miradas sobre la problemática. En gran medida, las ventajas metodológicas que ofrece el primero de estos proyectos para el campo de las políticas culturales han permitido consolidar su posición privilegiada en la opinión pública. Desde su trinchera cuantitativa, este tipo de investigaciones sobresalen por el alcance y operatividad de los datos, aun cuando sus procedimientos sean perfectibles. Desde sus primeros ensayos en los años 50 y 60, las encuestas de lectura han ido reflexionando acerca de sus principales dificultades en términos de método, desarrollando estrategias para lidiar, por ejemplo, con la diferencia entre las prácticas reales y las prácticas declaradas, o los obstáculos para medir la intensidad de la lectura (Donnat). Este tipo de saberes ha hecho posible la construcción de una mirada macro acerca de las prácticas lectoras, detectando los desafíos estructurales que éste depara. Sin embargo, sus bases conceptuales y metodológicas han redundado también en algunos sesgos significativos, frente a los que nuestra segunda opción teórica tendría, aún hoy, ciertas cosas que decir. Podemos sintetizar estas discusiones en tres puntos críticos.

En primer término, sigue resultando necesario generar conocimientos acerca de las experiencias de los lectores con los textos, más allá de las jerarquías preconcebidas sobre el valor social y simbólico de las obras. Como ha señalado B. Lahire, la sociología de la lectura ha entendido estas prácticas desde una visión del consumo cultural que, intentando situar los textos en su legitimidad social, frecuentemente los reduce a "los nombres de los autores, a los títulos o a las categorías genéricas a las que se supone que pertenecen" (Lahire 187). Sabemos que los bienes culturales son capaces de condensar múltiples connotaciones simbólicas y que en ellas tienen lugar tanto las representaciones hegemónicas como los procesos autónomos de significación. Hacen falta, en este sentido, estudios que sean capaces de 
abordar los contenidos de esas experiencias interrogándose qué es lo que la gente hace con las obras en el curso de su vida social.

Resulta preciso, entonces, ampliar y diversificar las unidades de medida que nos permiten aprehender los procesos de lectura. Los pocos estudios que se ocupan hoy de indagar en las prácticas sociales de lectura siguen construyendo su análisis desde el libro como formato de lectura privilegiado (Pellicer 2). En México y América Latina, las encuestas que guían las políticas oficiales han dado lugar a una serie de sentencias recibidas con preocupación desde distintos sectores, en las que se subraya cuantitativamente los débiles hábitos de lectura de los ciudadanos ${ }^{3}$. El peso gravitante que tiene el libro como unidad de medida de los hábitos lectores termina marcando un diagnóstico pesimista y alarmante. Así, podemos, encontrar en la prensa y la opinión pública aseveraciones tajantes que señalan que los nuestros son países "de no lectores", o donde "la gente no entiende lo que lee". Para darle a estas afirmaciones una justa medida, es necesario desanclar la mirada de los libros - y más aún, de los libros editados - y registrar las muchas prácticas lectoras contemporáneas que suceden al margen de éstos ${ }^{4}$. En este sentido, las investigaciones actuales deben autonomizarse de los intereses tradicionales de los editores, para indagar sin prejuicios en lo que está sucediendo con la lectura en sus modalidades y soportes emergentes, que sin duda incluyen piratería y circulación no autorizada de contenidos.

En tercer término, resulta preciso cuestionar la arraigada imagen del lector como figura solitaria e introspectiva, poniendo de relieve las dimensiones de la lectura que se activan y cobran sentido en colectividad. Como se ha señalado respecto de otras formas de consumo cultural, la recepción de los bienes simbólicos no puede ser pensada como la interacción solitaria entre individuos y productos (Campos), sino que sucede en el marco de una amplia red de relaciones sociales. Dicha dimensión colectiva puede resultar más evidente en

Por ejemplo, el primer informe de la Encuesta Nacional de Lectura 2012, intitulado sintomáticamente "De la penumbra a la oscuridad", consigna que en dicho país se lee un promedio de 2,94 libros por persona al año, y que menos de la mitad de la población mayor de 12 años lee libros.

$4 \quad$ Incluso dentro de este campo, algunos "editores del siglo XXI" han comprendido la magnitud de esta transformación, aseverando que la unidad-libro está desapareciendo de la escena y ganando porosidad en sus límites: "el valor de la cadena se desplaza desde un modelo que entremezcla contenido y distribución, hacia un modelo que valora simplemente el contenido" (Lloyd 2008: 7). 
otras formas de consumo cultural -como en el caso de espectáculos y conciertos (Cruces)-, pero también en la lectura están presentes la interlocución y la sociabilidad. Leer puede cobrar la forma de una conversación con libreros, amigos y/o profesores: de acuerdo con N. García Canclini,

ser lector es una relación social, una práctica comunicativa. A través de los siglos solo en ciertas situaciones la lectura ha sido una tarea silenciosa: en los conventos, en las bibliotecas, o, gracias a la multiplicación industrial de los libros, en el aislamiento de la casa. La lectura oral y colectiva ha predominado en la misma vida monástica, en las fábricas de cigarros, en la radio, los salones de clase y los congresos. El sentido social del acto de leer se intensificó por la cantidad de intermediarios que intervienen en el proceso de escritura, edición, difusión, lectura y uso de lo que se lee (7).

Las nuevas condiciones de reproducción y circulación de la lectura reactualizan, entonces, su vínculo con la creación de lazos sociales.

Estos tres sesgos de los estudios en torno a la lectura -un lector pasivo; que solo lee libros editados; y que lo hace en solitario-dan urgencia a la tarea de complementar los datos cuantitativos existentes con investigaciones más flexibles y comprensivas de las experiencias de los lectores. Ello no implica desconocer los aspectos sombríos de estos diagnósticos, ni los significativos desafíos que la promoción de la lectura enfrenta en estos tiempos. En este texto, queremos describir aquella amplia gama de prácticas de sociabilidad que hoy convoca la lectura, tomando los modos de lectura de los creadores culturales, con todas sus particularidades, como territorio de exploración. Sabemos que esta cualidad social de la lectura no constituye una novedad introducida por los medios digitales, pero observamos que se ve acentuada de distintas formas con las dinámicas de las nuevas tecnologías. Bob Stein viene desarrollando un conjunto de ideas que apuntan la mirada en esta dirección: con el autor y el lector conviviendo en el mismo espacio visual -el Internet-, se hace posible distinguir un vínculo horizontal que había permanecido disperso en la dinámica tradicional del libro impreso. "Mover los textos de la página a la pantalla no los hace sociales sino que permite que sus componentes sociales se pongan a la disposición de cualquiera y se multipliquen en valor [...]. Nuestros nietos asumirán que leer con otros, por ejemplo, la lectura social, es la manera 'natural' de leer. Les sorprenderá darse cuenta de que en nuestros días la lectura era algo que se hacía en soledad” (Stein). 
Pensar las reverberaciones sociales de la lectura en la sociedad contemporánea implica interrogar los límites que la separan de otras acciones que implican leer o escribir: chatear, postear, publicar, estar conectado. ¿Qué distingue las prácticas de lectura respecto de otros procesos de consumo o intercambio de información? ¿Debemos tratar del mismo modo el acto de leer un mensaje en el celular, y el de desentrañar las diversas capas de significado de una novela? Los propios informantes de nuestro estudio hacen distinciones en este sentido: en su diario de autoseguimiento, un escritor de treinta años diferencia las lecturas literarias y las lecturas fácticas. "Tomo prestado el término de las ciencias de la comunicación-dice, dando cuenta del segundo concepto-. Lecturas para iniciar, mantener, prolongar o interrumpir actos comunicativos. [...]. Lecturas como hechos cotidianos que me permiten funcionar".

Buena parte de la textualidad que se produce mediante los dispositivos tecnológicos opera como una clara extensión de la sociabilidad presencial: las tecnologías ofrecen la posibilidad de restituir la interacción social allí donde media una distancia entre los interlocutores. Solemos asociar el acto de leer a algo que entraña distancia en el tiempo o en el espacio, y de este modo, frecuentemente tenemos dificultades para entender instancias como el chat y las redes sociales como prácticas de lectura, puesto que están volcadas hacia la inmediatez y enfocadas en franquear esas lejanías. El texto, las imágenes y los videos se convierten, en estos contextos, en herramientas que extienden la sociabilidad mediante vías no presenciales. Sin embargo, como han apuntado diversos autores, el acto de leer es siempre el de sostener conversaciones desplazadas en el tiempo. La lectura de un ensayo y la de un correo electrónico constituyen, de este modo, prácticas de decodificación comparables, cada una de las cuales supone interlocutores tácitos y posibilidades de réplica. Los medios digitales han evidenciado el carácter dialógico y social que yace en toda práctica de lectura, acortando virtualmente la distancia entre la emisión y la recepción; entre el autor y el lector; y entre las interlocuciones y sus respuestas. Condensan en el tiempo y el espacio una naturaleza social que nunca estuvo del todo ausente, aunque sí dispersa, en las prácticas de lectoescritura.

Este estudio, enfocado en las prácticas lectoras de los creadores culturales, señala significativas transformaciones en este sentido. Procesos de sociabilidad lectora que solían encontrarse dilatados en el tiempo, han sido concentrados dando lugar a un intercambio fluido que supone nuevas dinámicas en el campo artístico y literario. De la misma forma, ciertas prácticas de discusión colectiva y de colaboración han alcanzado nuevos desarrollos con el surgimiento de los 
recursos digitales. A continuación, indicaremos tres puntos que nos permiten ver cómo los actuales modos de leer involucran nuevos sentidos de lo social: a) las transformaciones en la dimensión social de la lectura; b) la discusión sobre las reconfiguraciones del autor; y c) la posibilidad de la colaboración como plataforma creativa.

\section{A. TRANSFORMACIONES EN LA DIMENSIÓN SOCIAL DE LA LECTURA}

Entre los informantes de este estudio existe consenso respecto de que los libros y los textos son objetos centrales en las experiencias de vida de los creadores culturales, tanto como herramientas para explorar sus propias sensibilidades, como en su capacidad de conectarlos con otros. "El texto es una cosa que se comparte", nos dice un joven artista, reflexionando en las formas de circulación que han tenido los libros a lo largo de su vida. "Realmente no hay lectura individual", señala una escritora de cincuenta años, quien apunta que buena parte de las conversaciones que ha iniciado en su vida han sido a partir de libros. "No hay lectura limitada al espacio de lo así llamado "íntimo'", La lectura genera complicidades, y activa un circuito de préstamos, recomendaciones, intercambios y regalos que afianzan las relaciones humanas. Casi todos nuestros entrevistados relacionan la lectura con sus mediaciones sociales, y la sitúan como una de las primeras vías para estrechar lazos entre las personas. "Yo creo que los textos, las lecturas, las peliculas, tejen afinidades. Construyen personas e individualidades. Son redes de conexiones... de trabajo, de amistad, y de desencuentros también", apunta un artista de veinte años. La formación de comunidades lectoras, sobre todo en la adolescencia y la juventud, se recuerda en muchos casos como una instancia crucial en la expansión de los horizontes sociales, a través de clubes de lectura o grupos de estudio universitarios. Más de algún artista o escritor consagrado recordó que, en sus años de formación, quienes disponían de muchos libros o de libros difíciles de conseguir, convocaban a sus amigos y compañeros para examinarlos en conjunto. Aparecían así referentes artísticos comunes que se admiraban o cuestionaban en colectivo. Los más jóvenes continúan desplegando esta estrategia, organizando círculos de lectura e ideando estrategias de reproducción y difusión de los textos que les resultan significativos: revistas en línea, fanzines, ediciones piratas.

Así, para muchos creadores culturales, la lectura no puede sino ser parte de su vida social. Los libros son objetos que movilizan afectos y proyectos en equipo. "Editar en colectividad; diseñar en colectividad también; comprar 
libros para después compartirlos; gestionar foros y espacios sobre el ámbito editorial... también son espacios sociales -afirma una curadora y editora-. Son una oportunidad de crear con otros". La gestación de los proyectos artísticos y literarios se fragua a la luz de múltiples conversaciones con amigos y colegas: surge una idea, se comenta entre los colaboradores cercanos, y adquiere resonancia. Difícilmente el proyecto podría concretarse sin la complicidad de un grupo que se reparte los papeles y discute las posibilidades. Se construye "desde una visión creativa compartida, una necesidad de resolver", afirma la misma entrevistada.

$\mathrm{Si}$ algo ha cambiado con la llegada de internet y las redes sociales es la posibilidad de hacer lo que hacíamos antes pero con otra velocidad, pues estamos conectados con otros con mucha mayor facilidad a una escala interplanetaria: "el Facebook es muy rápido y le da una nueva velocidad a las conversaciones", dice una joven artista visual. Nuestros informantes coinciden en que el ciclo se ha acortado, y que el ritmo con el que se construyen, reproducen y desarticulan las comunidades de lectores es definitivamente más vertiginoso5. "Los libros generaban comunidades lectoras, pero las comunidades lectoras tomaban un tiempo para desarrollarse y tomar una fuerza especifica-comenta un editor independiente-[...]. Ahora eso sucede mucho más rápido, y además es público, no es solo una cosa privada, intima". Como la red ofrece una plataforma más accesible y con menos barreras que los espacios de discusión tradicionales, cualquiera puede intervenir en estas discusiones, lo que en general es visto como un cambio positivo. Por otra parte, los vínculos que se establecen en las comunidades digitales tienden a ser más superficiales y efímeros que los basados en la copresencia, e incluso que aquellos de las comunidades articuladas desde los diarios y revistas de circulación nacional, que implicaban 'pensar bien' las respuestas y seguir las polémicas durante semanas. "Ahora es más fácil crear comunidades lectoras -apunta un escritor joven-, pero creo que son más superficiales que antes". Hay quienes apuntan, en este mismo sentido, que este desplazamiento hacia el mundo digital no ha sido capaz de desarrollar el mismo nivel de

Un fenómeno significativo en este sentido es la llamada fan fiction, en la que los lectores llevan a los protagonistas de sus libros favoritos a nuevos escenarios ficcionales, esta vez narrados por ellos. Estas particulares comunidades de lectores son un claro ejemplo del papel que la sociabilidad ocupa en las prácticas emergentes de lectura. No ahondaremos, sin embargo, en estas formas específicas del vínculo lector, pues no suelen estar asociadas a la población de estudio que abordamos en esta ocasión: los creadores culturales. 
análisis y profundidad que tenían los intercambios en presencia. Una joven escritora reflexiona en su diario de lectura: "La conversación presencial sigue conservando la fuerza del verdadero debate e intercambio de ideas, y el libro en papel sigue siendo la representación del tiempo, el análisis y la pausa en un mundo donde todo circula hacia donde sea, imperativamente". Para otros, un poco más optimistas, las redes sociales facilitan la cohesión de una red y el intercambio entre sus miembros: "hay una comunidad de escritores jóvenes que están muy conectados -nos dice en este sentido una poeta de esta misma generación-. Tengo gente que no conozco en Facebook, pero los tengo aceptados porque son amigos de amigos que sé que pertenecen a este círculo, y me interesa ver qué están haciendo mis contemporáneos". Las redes sociales han expresado esta dimensión social de la lectura de formas insospechadas, multiplicando los vínculos y generando sinergias entre los colaboradores: si siempre pudimos encontrar rayados y comentarios de los lectores en los libros de las bibliotecas, hoy existen aplicaciones específicas para compartir esas impresiones y agrupar a los lectores. Existen hashtags para compartir bibliografías y comentar las lecturas hechas dentro de circuitos culturales específicos. Con todo ello -reflexiona una escritora de la generación de arriba-, comienzas a entenderte menos a ti mismo como el eje de las lecturas, para dejar este lugar de la agencia a otros: te abres a las recomendaciones y a las sorpresas. "La sorpresa permite lecturas más críticas, y genera una relación más abierta y más dúctil con el mundo”, afirma. Estas convergencias en un nuevo terreno público facilitan la tarea de mapear el campo, familiarizarse con autores y textos, acceder a los libros y situar la propia producción dentro del escenario contemporáneo.

Parece haber cierto consenso: los ritmos del intercambio se han transformado. Algunos escritores destacan que una contienda literaria podía durar varias semanas de textos y réplicas en los suplementos culturales, en intervalos definidos por el día de publicación de la revista. "Ahora las respuestas se han diversificado, y resultan mucho más viscerales... siempre hay respuestas inteligentes, pero siempre tienen esta prisa", nos dice otro escritor de cerca de treinta años, usuario de los medios digitales. Así, los espacios prestigiosos donde antaño el debate se concentraba se han visto diseminados, y las conversaciones en torno a los libros ocurren de forma simultánea en numerosos frentes virtuales. Los viejos referentes no han desaparecido, afirma este entrevistado, pero su papel ha sido matizado: "Esos espacios prestigiosos siguen funcionando como detonadores de la discusión o como 
nodos importantes, pero la discusión en realidad está en muchos soportes. Está atomizada, o más que atomizada, está diversificada”.

En este panorama emergente de la lectura, que combina soportes tradicionales y nuevas tecnologías, los creadores culturales experimentan dinámicas sociales moldeadas por los vínculos virtuales y los presenciales; por los cruces entre lo online y lo offline. En este sentido, una joven escritora nos comenta: "una diferencia importante que noto ahora es que construyo relaciones con gente que no veo. Tengo varios casos de personas muy cercanas virtualmente, que he encontrado por afinidades de lectura y musicales". Este tipo de vínculos reconfigura los modos en que se estructura la sociabilidad en el campo, expandiéndolos hacia intercambios inéditos hasta ahora. Las dinámicas offline no han cambiado mucho: todavía existen grupos de lectura o discusión, eventos literarios y artísticos como las presentaciones de libros y exposiciones. Pero el terreno online ha crecido e incluso ha sustituido algunas de las interacciones offline: las discusiones sobre libros y exposiciones, por ejemplo, suceden más a menudo en las redes sociales, y casi siempre a partir de alguna reseña o texto que circula de forma digital. Pareciera haber un proceso cíclico que va del mundo offline al online y viceversa. Nuestras observaciones a partir de los detallados diarios de lectura de los creadores culturales destacan la importancia de las plataformas digitales para la elaboración crítica de las lecturas, dadas sus potencialidades como espacios de discusión colectiva. Facebook, Twitter, Pinterest y Tumblr fueron algunas de las redes sociales que aparecieron con frecuencia en las autoetnografías de lectura, donde los artistas y escritores comentaban qué usos daban y cómo daban salida a los textos que estaban leyendo. Ello no anula las interacciones tradicionales que las lecturas activan: la conversación presencial o telefónica sigue siendo un aspecto significativo del ciclo de la lectura de los creadores culturales, y se manifiesta en una diversidad de escenarios y formas:

\section{Domingo 13 de julio}

\subsection{0- 2.30 (madrugada)}

Leo los textos que acompañan la antología musical de Javier Álvarez, Progresión. Lo hago porque Javier es un buen amigo hace muchos años. Me regaló su antología y habiendo ido a su presentación un par de días antes, y con la conversación continua que tenemos acerca de nuestros respectivos trabajos (artes visuales y composición) me quedo con una enorme curiosidad de leer completos los textos [...]. Tomo nota mental de estudiar más a fondo el concepto del color en la música, y de cómo se relaciona con la pintura. 
Al día siguiente lo comento con mi hermano, quien ni siquiera sabía que existía tal cosa. Me prometo hablarlo más a fondo con Javier y con otro amigo compositor.

(artista visual, 43 años)

\section{Martes 24 de junio}

Por lo general siempre comento las noticias con J., mi pareja, él me pasa enlaces de otras páginas y le damos vueltas un rato al asunto. Algo que nos llama mucho la atención de las noticias que salen en las versiones en línea de los diarios de circulación nacional son siempre las reacciones de los lectores; nos sorprende la cantidad de odio y la escasa argumentación que se despliega en los comentarios de las notas.

(escritora, 32 años)

\section{Miércoles 18 de junio.}

Por la mañana. En efecto las referencias me fueron útiles y el texto de Paz (mis copias se las di a Mariana), le puede aportar para su proyecto. Me sorprende que siempre voy por ahí hablando de referencias y textos que daría por hecho que los jóvenes conocen y no es así. Aunque otros maestros que han participado en el diplomado les dejaron lecturas (archivos digitales, ¡ni siquiera tienen que ir por el libro a la biblioteca!) no leen nada. Por lo tanto no discuten nada y no tienen preguntas específicas.

(artista visual, 48 años)

Estas nuevas posibilidades digitales han abierto diálogos entre los distintos autores, y también entre autores y lectores. Todo ello implica que, en la vida virtual, se hace necesario gestionar las relaciones dentro y fuera de la red, prestándose en ocasiones para la existencia de 'personalidades desdobladas'. Uno de nuestros entrevistados lo relata así: "puedes ir a un encuentro de escritores y notas una diferencia entre la convivencia de una comunidad online y la convivencia de la comunidad offline. [...] Creo que no somos tan generosos offline como online, porque eres generoso con tu propia plataforma y con la construcción de ti mismo a través de tu plataforma". Si haces una pregunta en línea siempre habrá quién te responda o te ayude a encontrar el dato que necesitas. En los encuentros presenciales, señala una joven escritora, siempre hay una mesa que te separa, un escenario y un público, un micrófono o una fiesta VIP. Las estructuras físicas, para bien o para mal, terminan por marcar las jerarquías, y no permiten una relación tan horizontal como las redes. 
Esto no quiere decir que el intercambio digital es del todo igualitario, o que lo presencial será reemplazado por las dinámicas de la red. A pesar de las contradicciones, hay complementariedad entre los dos ámbitos. Las ferias de arte y las ferias del libro, junto a sus actividades asociadas, alcanzan cada año cifras inéditas de público, y las exposiciones o festivales de poesía siguen congregando físicamente a los creadores del circuito. Se trata de instancias de encuentro fundamentales para el desenvolvimiento del campo: allí se congregan, discuten e imaginan nuevos emprendimientos. Estos espacios ya no son las únicas vías para acercar a los autores y los lectores, pero continúan siendo vitales para que el circuito se reúna de forma periódica. "A los autores les cuesta todavía mucho trabajo no lanzar sus libros", apunta un editor independiente. Estas formas de la presencialidad se resisten al olvido, en parte, porque sigue siendo necesario para los creadores la construcción de su figura en tanto autor.

\section{B. RECONFIGURACIONES DE LA AUTORÍA}

En los ámbitos en que se desenvuelven nuestros informantes, las prácticas de lectura se encuentran estrechamente vinculadas a la propia producción escritural, y en torno a ella prima una mirada crítica que atraviesa tanto a las artes visuales como a la literatura contemporánea. Las distintas percepciones recogidas en este estudio nos hablan de la disolución del autor como genio creador autónomo e individual: se aboga en estos campos por un tráfico libre de conocimientos; se celebra la apropiación como recurso válido para la creación artística y escritural; y se desestima la originalidad como una ficción romántica que debe ser puesta en tela de juicio. "Cuando Barthes dijo que el texto es una colección de citas de distintas fuentes de la cultura-resume una entrevistada-, estaba describiendo puntualmente lo que hacemos cuando escribimos libros. Y creo que la tecnología ha puesto muy en claro que eso es cierto, y que esas nociones de originalidad y de singularidad y de individuo en el proceso creativo son más bien producto de una cierta noción de lo que es la subjetividad y la subjetivización, y no necesariamente un proceso directo y natural". La figura del autor, apunta Jenkins, tiene origen en el marco de una configuración económica, jurídica y social muy específica, de modo que no debe extrañarnos que pierda importancia en la medida en que "el sistema de las comunicaciones y de las relaciones sociales se transforma, desestabilizando el humus cultural que había visto crecer su importancia" (Jenkins 126). 
Así como hay nuevas formas de ser autor y ser lector, también encontramos resistencias y lógicas atávicas. Muchos de nuestros entrevistados se sienten más cerca de sus lectores y espectadores, con todas las consecuencias positivas (lecturas críticas) y negativas (insultos, persecuciones) que ello acarrea. "Ahora podemos saber la opinión de todo mundo", nos dice un escritor de 47 años. Hoy en día un escritor puede publicar un texto en una revista en línea y recibir comentarios de sus lectores al minuto. "Antes pasaban semanas, meses o años hasta que sabias lo que alguien habia pensado del texto que escribiste, o para enterarte de que efectivamente alguien lo leyó", continúa nuestro entrevistado. En este sentido, teóricos como Bob Stein auguran que esta relación entre autor y lector será cada vez más porosa. A la vez, los emisores se multiplican y hay espacio para nuevas voces. "Leo autorías mucho más variadas que antes. Leo mucho más jóvenes. Leo a gente que no necesariamente ha publicado en papel", resume una escritora de cincuenta años. El "parnaso" inalcanzable de los escritores y los intelectuales ha sido en cierto sentido desmitificado, y ahora resulta posible acceder a muchos de ellos a través de canales múltiples.

El cuestionamiento de las autorías tradicionales no está exento de contradicciones ni deja de resultar problemático a nivel de prácticas. Las remuneraciones y los reconocimientos suelen ser una fuente de conflictos, y terminan por traslucir que ciertas lógicas de la autoría tradicional -como la jerarquía entre los distintos tipos de trabajo en la creación artísticacontinúan vigentes. Una artista que ha decidido construir su obra a partir de un proyecto editorial colectivo se encuentra a menudo con problemas para capitalizar estos esfuerzos: "en la Revista muy pocas veces aparece mi nombre -nos comenta-, y de pronto hay problemas curriculares. Me piden que demuestre: "pero aqui no aparece tu nombre". También es una lucha contra la burocracia y la institución y todo esto, que exige que haya nombres y jerarquias". Cuando los proyectos artísticos se plantean de forma colectiva y sus productos pertenecen a la comunidad, resulta difícil determinar quién percibe los ingresos o cómo deben distribuirse éstos. "Al final la gente quiere seguir cobrando y quiere seguir firmando sus textos", asevera un escritor. Así, pese al discurso imperante, los modos de legitimación en los circuitos culturales todavía están ligados al nombre propio; pues "seguimos leyendo las cosas que leyó tal y que retuiteó tal y no tal otra persona”. La mayor parte de nuestros informantes plantearía que el problema autoral sigue en un espacio de indeterminación: "no creo que nunca se resuelva la contradicción -señala uno de ellos-, se irán generando pequeños matices para lidiar con 
ella, pero se irán diseñando cada vez estrategias para transgredirla, porque hay una evidente contradicción en decir: 'La producción es colectiva y de la comunidad, pero yo quiero ser remunerado'”. De acuerdo con Cristina Rivera Garza, quien desarrolla ampliamente la idea de desapropiación en su libro Los muertos indóciles (88), los procesos de apropiación que no son adecuadamente cuestionados -desapropiados- incurren en un peligro tan grande como el de no haber criticado jamás la autoría. Así, regresamos al punto de partida: ¿cómo dejar atrás el nombre cuando las estructuras de la creación artística aún no se actualizan respecto de estas discusiones contemporáneas? Quienes trabajan de forma más práctica utilizan formatos conocidos como: "en colaboración con", o le dan un nombre al colectivo y, a su vez, el nombre de cada individualidad que lo conforma. Al respecto, un artista visual de 45 años nos comenta: "Se crea un problema de valor en el mercado.[...] Estamos acostumbrados a esta racionalidad económica en que el valor está asociado con un autor identificable".

Por otra parte, en lo que respecta a los nuevos soportes, los recursos digitales permiten la emergencia de espacios más laxos y menos ortodoxos para la realización de las obras, asociados a nuevas temporalidades y dispositivos que redundan en nuevas formas de lectura. Numerosos proyectos visuales existen únicamente en una página web o suceden durante un lapso específico de tiempo en las redes sociales; hay escritores que ensayan frases o novelas enteras en Twitter, o que se replantean su forma de "aparecer" en el medio renunciando a la publicación tradicional en papel, convirtiendo sus libros en páginas web.

En este panorama confuso en el que se funden algunos aspectos de las autorías tradicionales y perviven otros, y en el que la lectura de obras no solo sucede en los libros sino también en plataformas múltiples, se reconfiguran también los criterios con los que los lectores se orientan y otorgan autoridad a las producciones culturales. Si alguna vez ciertas instituciones y las revistas culturales desempeñaron un papel de faro para ordenar las escrituras "legítimas", con el advenimiento de internet esta capacidad de autorizar nombres y obras recae más bien en ciertos personajes: intelectuales de renombre, tuiteros influyentes u otros actores del campo artístico cuya opinión sirve de referencia para los recién llegados. "Hay un desplazamiento de las instituciones, como las revistas, a los personajes que están vinculados con ciertas revistas", nos dice un poeta y académico de cerca de treinta años. Más allá de esas coordenadas, encontrar material confiable en internet puede ser una tarea difícil de no contar con ciertas herramientas para discriminar entre la gran 
cantidad de textualidad que se produce. "En papel sabes quién es legítimo y quién no; hay una cultura desarrollada en ese sentido. Es relativamente fácil para un lector mínimamente formado identificar fuentes legítimas de información. Pero en la red apenas lo estamos aprendiendo", nos dice un artista y creador del medio digital. Además de ciertos aspectos de diseño y formato que entregan pistas considerables, la dimensión social es un filtro importante a la hora de aplicar criterios, pues son los amigos y compañeros quienes van direccionando estas búsquedas, y la colectividad que se genera con las redes digitales hace posible mapear los territorios creativos.

\section{LECTORÍAS COLABORATIVAS Y PLATAFORMAS DE CREACIÓN}

En este último punto, prestaremos atención a los usos específicos que los creadores dan a las prácticas de lectoescritura en el marco de proyectos colaborativos. Sabemos que, antes y después de internet, leer y escribir son actividades centrales para el desarrollo de proyectos cooperativos de creación, pues la trama de actores que interviene en ellos parte de una serie de convenciones que no pueden comprenderse sin éstas (Becker). Hoy, la colaboración sucede tanto dentro como fuera de las redes digitales, y nuevamente aquí la relación entre lo presencial y lo virtuales de retroalimentación y complemento. La lectura puede ser, como demuestran distintas iniciativas artísticas que observamos en nuestro trabajo de campo, una vía para el fortalecimiento de la comunidad: bibliotecas especializadas, colectivas o transhumantes, o talleres de lectura como el que este joven del ámbito literario realiza con familias otomíes:

\section{Lunes 21 de julio}

Son las 12:30. La lectura de este libro ha sido mi primera lectura literaria del día. Leí para comunicarme con los niños. Para hacerlos imaginar la historia a través de las imágenes. [...] La lectura los va abriendo a nosotros, un grupo de desconocidos que ha ido tres veces a leerles. Y con el libro ellos van descubriendo y aprendiendo cosas. No sé bien qué. No sé qué impacto tenga. Trato de divertirme con ellos y ya. De confiar en que la ficción se va incorporando y genera cosas, palabras, conversaciones, silencios para pensar, para disfrutar. Queremos formar una biblioteca comunitaria, pero antes de abrirla necesitamos conocer a la comunidad. Los libros son la herramienta. La lectura, el lazo. (escritor, 31 años) 
La conectividad contemporánea ofrece acceso a plataformas que hacen posible no solo comentar de forma colectiva, sino que también producir obras entre muchos creadores, incluso estando éstos dispersos en términos geográficos. "Las redes sociales agilizan y ayudan a la colaboración”, afirma un joven narrador, al comentar un proyecto colectivo de traducción que emprendió a través de Twitter. Con una amiga, señala, decidieron utilizar su tiempo libre para traducir un libro entre ambos. Cada vez que alguno de los dos tiene tiempo, traduce una línea y la tuitea y así, poco a poco, se genera un producto que atraviesa las redes sociales, es decir, que se hace público al tiempo en que se produce. Otro entrevistado nos cuenta que a veces utiliza las redes para preguntarle a sus lectores qué les parecería si a su personaje $\mathrm{x}$ le sucede tal o cual cosa. Los artistas visuales, por su parte, utilizan continuamente Skype para discutir las exposiciones o piezas colectivas, compartiendo información, textos o links para el desarrollo de sus proyectos. Todos estos relatos parecen señalar que las plataformas digitales han hecho expeditas las relaciones y proporcionado un sinnúmero de nuevas herramientas a la colaboración artística, potenciando el discurso de colectividad que prima en buena parte de las escenas contemporáneas. Como ha señalado H. Jenkins, la cibercultura que enmarca estas prácticas hace emerger formas de inteligencia colectiva que se caracterizan por ser participativas, socializantes y abiertas; sin embargo, el contrapunto de estas dimensiones emancipadoras es la inevitable aceleración de la mutación técnica que esta inteligencia colectiva lleva aparejada. En otras palabras, el potencial incluyente de estas prácticas deviene en una suerte de exclusión de segundo orden, que se manifiesta de forma muy clara cuando comparamos las competencias de los creadores culturales con otras poblaciones de estudio. "La inteligencia colectiva que favorece la cibercultura es a la vez veneno para aquellos que no participan $[\ldots]$ y remedio para aquellos que se sumergen en sus remolinos y consiguen controlar su deriva en medio de esas corrientes" (Jenkins 15).

Aunque cada vez son más comunes estas iniciativas de autorías desdibujadas y domicilio digital, las instituciones, becas y premios han demostrado dificultades para admitir estas nuevas modalidades de producción como proyectos creativos válidos. "Los concursos piden que los libros no estén publicados en blogs -nos cuenta, molesta, una poeta joven que se desenvuelve en los medios digitales-. Yo prefiero renunciar al concurso que a la posibilidad de escribir un libro a cien manos, y tener un registro de qué es lo que voy escribiendo", sentencia. Las potencialidades múltiples que ofrecen las redes multimediales todavía no terminan de ser exploradas, en parte porque 
éstas y otras reticencias desalientan los esfuerzos en este sentido. Se vuelve urgente, en este sentido, poner sobre la mesa las discusiones relativas a los nuevos estatutos de la información y los reglamentos -tácitos y legales-que la gobiernan, con el objeto de llegar a nuevos consensos que vayan a la par del desarrollo creativo y artístico. Vemos que los creadores culturales hacen usos resueltos de los recursos digitales, desafían los límites de la propiedad intelectual tradicional y celebran los intercambios colaborativos que optimizan los procesos artísticos. Muchos de ellos se muestran particularmente interesados -o directamente involucrados- en la creación de nuevos espacios en internet, apoyando la gestación de software libres que permitan un acceso cada vez más abierto a la información y la generación de verdaderas comunidades de lectores. En este sentido, los modos de leer y de compartir a través de la lectura de los creadores culturales pueden ser evidencias significativas a la hora de construir una cultura con acceso amplio e igualitario no solo a la información, sino también a las habilidades para usarla.

\section{SOCIABILIDADES EMERGENTES EN TIEMPOS DIGITALES}

La experiencia lectora de los creadores culturales que participaron en esta investigación parece indicar que la incorporación de nuevas tecnologías en las prácticas de lectoescritura activa y da nuevos cursos a ciertas dimensiones de sociabilidad que siempre han estado presentes en ellas. Así, si siempre hemos leído con otros, los artistas y escritores nos demuestran que el intensificar este nivel "conversacional" (Leveratto y Leontsini 37) de los textos puede ser un ejercicio fecundo, ya que estos intercambios son a menudo la semilla de nuevos proyectos creativos. La multiplicación de las pantallas y las nuevas posibilidades de interacción que éstas ofrecen no son sinónimo unívoco de formas de lectura personalizadas y centradas en el individuo. También se producen nuevas dinámicas donde la red de lectores adquiere un nuevo protagonismo, afectando no solo los modos en que se lee y se comparte lo leído, sino también reformulando diversos aspectos de la propia producción artística y cultural. La colaboración artística contemporánea está profundamente atravesada por prácticas de lectoescritura, que abarcan niveles distintos de conectividad social y de reflexividad subjetiva. En este sentido, la riqueza de las plataformas digitales es su capacidad de hacer converger no solo una multiplicidad de textualidades (tuits, mails, imágenes, archivos de word, videos, etc.), sino también de actores en torno a un proyecto creativo, pues permiten 
franquear las distancias físicas y temporales en pos de una construcción conjunta. De este modo, el ejemplo de los creadores culturales nos señala que, en el escenario contemporáneo, no solo es preciso incorporar competencias vinculadas a la transliteracidad, entendida como la "capacidad de leer, escribir e interactuar a través de una gama de plataformas, herramientas y medios de comunicación desde la oralidad a la escritura, televisión, radio y cine, o redes sociales digitales" (Martos y Campos 10). También es preciso activar el potencial de conversación de estas interacciones digitales, que encuentran en la cibercultura un entorno idóneo para desplegar la inteligencia colectiva y desarrollar prácticas basadas en el procomún.

En sus ángulos más productivos, la idea de sociabilidad no se restringe a aquella dimensión colectiva inherente a los libros, sino que va un paso más allá: se distingue de la socialización -o vínculo social en sentido generalpor su independencia frente al interés económico y social, o la incapacidad de reducirlo a ello. La sociabilidad, liberada del reino de las necesidades, se despliega en toda su extensión en el marco del ámbito democrático, y podría ser definida como la "aptitud para vivir en grupo y para consolidar los grupos por la constitución de asociaciones voluntarias", como afirma M. Agulhon (cit. en Dosse 57). Las experiencias de lectura de los artistas visuales y escritores parecen indicar que esta dimensión de colectividad electiva está en el centro de una vida lectora gozosa y productiva. La lectura convoca afinidades y desarrolla vínculos cómplices, afianzando los lazos sociales y contribuyendo al desarrollo de una sociedad abierta al diálogo. Por ello, la promoción de la lectura no puede concentrar todos sus esfuerzos en la generación de lectores singulares e introspectivos, no obstante éstos sigan siendo imprescindibles. Así, resulta preciso complementar las estrategias actuales de las políticas lectoras ${ }^{6}$ con nuevos mensajes que pongan de relieve este vínculo entre lectura y sociabilidad: la lectura sirve para conectar con otros; es una experiencia social y colectiva; y desarrolla los valores que sustentan la vida democrática.

\footnotetext{
En el caso de México, estas políticas han adoptado tópicos recurrentes en los últimos años, tal y como atestiguan las campañas de fomento lector de instituciones públicas (como Metro de la Ciudad de México), y privadas (como editoriales y librerías locales, y entidades gremiales como el Consejo de la Comunicación). Podríamos sintetizar estas estrategias a partir de tres recursos generales: la lectura como viaje; la lectura como herramienta de crecimiento personal o recurso útil para la vida; y la lectura como un hábito o como parte de la vida cotidiana.
} 
Los hallazgos de esta investigación constituyen evidencia significativa de que estas formas de sociabilidad activan el potencial gozoso que atraviesa las prácticas de lectura contemporáneas. De este modo, el desarrollo de programas educativos o de intervención social -tanto en México como en el resto de América Latina- no debe desconocer estas dimensiones del problema, ni dar por hecho una supuesta competencia entre la lectura (física o digital) y otras prácticas sociales marcadas por una trama de sociabilidad y presencia. Del mismo modo, basándonos en estas experiencias, podemos levantar una crítica en torno a aquellos imaginarios que entienden los nuevos desarrollos tecnológicos como formas de retroceso de la vida colectiva y del intercambio social. Lejos de constituir lectores individuales y aislados, las posibilidades que entregan las formas digitales de lectura -desde los e-book a las redes sociales y plataformas web- pueden hacer emerger renovados vínculos de sociabilidad entre los sujetos.

\section{BIBLIOGRAFÍA}

Becker, Howard. Los mundos del arte: sociología del trabajo artístico. Buenos Aires: Universidad Nacional de Quilmes Editorial, 2008.

Bourdieu, Pierre. La distinción. México DF: Taurus Pensamiento, 2012.

Bourdieu, Pierre y Roger Chartier. "La lectura: una práctica cultural”. En Bourdieu, Pierre, El sentido social del gusto. Elementos para una sociología de la cultura. Buenos Aires: Siglo XXI Editores, 2011.

Campos, Luis. "El consumo cultural: una actividad situada". En Güell, Pedro y Tomás Peters (comps). La trama social de las prácticas culturales. Santiago: Universidad Alberto Hurtado, 2012.

Chartier, Anne Marie y Jean Hébrard. La lectura de un siglo a otro. Discursos sobre la lectura (1980-2000). Barcelona: Gedisa, 2002.

Cruces, Francisco. "Con mucha marcha. El concierto pop-rock como contexto de participación". Trans. Revista transcultural de música 4, 1999.

De Certeau, Michel. La invención de lo cotidiano. Vol I: Artes de hacer. México DF: Universidad Iberoamericana, 1996.

Donnat, Olivier. "Encuestas sobre los comportamientos de lectura. Cuestiones de método". Lahire, Bernard, comp. Sociología de la lectura. Barcelona: Gedisa, 2004.

Dosse, François. La marcha de las ideas. Historia de los intelectuales, historia intelectual. Valencia, Universidad de Valencia, 2007.

Encuesta Nacional de Lectura. "De la penumbra a la oscuridad... Primer informe". México: Fundación Mexicana para el Fomento de la Lectura, A.C, 2012. 
García Canclini, Néstor. "Las ferias en una época en que se venden menos libros y se lee más”, 2014 (inédito).

Gerber, Verónica y Carla Pinochet. "Cómo leen los que escriben con textos e imágenes”. En García Canclini, Néstor (ed.): Hacia una antropología de los lectores. México DF: Ariel/ UAM/ Fundación Telefónica, 2015.

Jenkins, Henry. Cibercultura. Informe al consejo de Europa. Barcelona/ Ciudad de México: Anthropos/ UAM, 2007.

Lahire, Bernard. "Del consumo cultural a las formas de la experiencia literaria". En Lahire, Bernard (comp.) Sociología de la lectura. Barcelona: Gedisa, 2004

Leveratto, Jean- Marc, y Mary Leontsini. Internet et la sociabilité littéraire. Paris: Bibliothèque publique d'information / Centre Pompidou, 2008.

Lloyd, Sara. "Manifiesto de una editora para el siglo XXI". Pan Macmillan Digital Publishing, 2008. http://libros.soybits.com/blog/manifiesto-sara-lloyd

Martos, Eloy y Campos, Mar. Diccionario de nuevas formas de lectura y escritura. España: Santillana, 2013.

Pellicer, Alejandra. “CCómo evaluar y entender al lector internauta y al lector en papel?”, 2006. (inédito)

Ricoeur, Paul. Tiempo y narración. México: Siglo XXI Editores, 1995.

Rivera Garza, Cristina. Los muertos indóciles. Necroescrituras y desapropiación. México DF: Tusquets, 2013.

Stein, Bob. "The Future of the Book is the Future of Society." If:book, 2013. http://futureofthebook. org $/ \mathrm{blog} / 2013 / 03 / 18 /$ the_future_of the_book_is_the/ 